OPEN ACCESS

Edited by:

Datta Madamwar,

Sardar Patel University, India

Reviewed by:

Mayur B. Kurade,

Hanyang University, South Korea

Liang Tan,

Liaoning Normal University, China

*Correspondence:

Ramadoss Dineshram

dinesh@nio.org;

dinbiot@gmail.com

Amit Kumar

amit.kumar.szn@gmail.com

Specialty section:

This article was submitted to

Microbiotechnology,

a section of the journal

Frontiers in Microbiology

Received: 12 August 2020 Accepted: 30 November 2020

Published: 21 December 2020

Citation:

John J, Dineshram R, Hemalatha KR,

Dhassiah MP, Gopal D and Kumar A (2020) Bio-Decolorization of

Synthetic Dyes by a Halophilic

Bacterium Salinivibrio sp..

Front. Microbiol. 11:594011.

doi: 10.3389/fmicb.2020.594011

\section{Bio-Decolorization of Synthetic Dyes by a Halophilic Bacterium Salinivibrio sp.}

\author{
Jojy John ${ }^{1,2}$, Ramadoss Dineshram ${ }^{1 *}$, Kaveripakam Raman Hemalatha ${ }^{3}$, Magesh \\ Peter Dhassiah ${ }^{4}$, Dharani Gopal ${ }^{4}$ and Amit Kumar ${ }^{2 *}$
}

\begin{abstract}
'Biological Oceanography Division, CSIR-National Institute of Oceanography, Dona Paula, India, ${ }^{2}$ International Research Centre for Climate Change Studies, Sathyabama Institute of Science and Technology, Chennai, India, ${ }^{3}$ Department of Microbiology, Annamalai University, Chidambaram, India, ${ }^{4}$ Department of Marine Biotechnology, National Institute of Ocean
\end{abstract} Technology, Chennai, India

Synthetic dyes, extensively used in various industries, act as pollutants in the aquatic environment, and pose a significant threat to living beings. In the present study, we assessed the potential of a halophilic bacterium Salinivibrio kushneri HTSP isolated from a saltpan for decolorization and bioremediation of synthetic dyes. The genomic assessment of this strain revealed the presence of genes encoding the enzymes involved in decolorization mechanisms including FMN-dependent NADH azoreductase Clade III, which cleave the azo bond of the dye, and the enzymes involved in deamination and isomerization of intermediate compounds. The dye decolorization assay was performed using this bacterial strain on three water-soluble dyes in different concentrations: Coomassie brilliant blue (CBB) G-250 (500-3,000 mg/L), Safranin, and Congo red (50-800 mg/L). Within 48 h, more than $80 \%$ of decolorization was observed in all tested concentrations of CBB G-250 and Congo red dyes. The rate of decolorization was the highest for Congo red followed by CBB G-250 and then Safranin. Using UV-Visible spectrometer and Fourier Transform Infrared (FTIR) analysis, peaks were observed in the colored and decolorized solutions. The results indicated a breakdown of dyes upon decolorization, as some peaks were shifted and lost for different vibrations of aromatic rings, aliphatic groups $\left(-\mathrm{CH}_{2},-\mathrm{CH}_{3}\right)$ and functional groups $\left(-\mathrm{NH},-\mathrm{SO}_{3} \mathrm{H}\right.$, and $\left.-\mathrm{SO}_{3}{ }^{-}\right)$in decolorized solutions. This study has shown the potential of $S$. kushneri HTSP to decolorize dyes in higher concentrations at a faster pace than previously reported bacterial strains. Thus, we propose that our isolated strain can be utilized as a potential dye decolorizer and biodegradative for wastewater treatment.

Keywords: phylogenetic analysis, bioremediation, azoreductase, dye decolorization, halophilic bacteria

\section{INTRODUCTION}

Dyes are organic coloring agents which are extensively used for coloring the products in various industries including textile, paper, cosmetic, and food (Vaghela et al., 2005). These coloring agents are complex aromatic structures which remain stable by resisting the impacts of temperature and other environmental factors (Pandey et al., 2007). Overall, more than 
thousands of dyes are generated commercially and $7 \times 10^{5}$ metric tons of dyes are produced annually (Amoozegar et al., 2011). Generally, based on their origin, the dyes are classified into natural and synthetic dyes. Natural dyes are obtained directly from plants, microbes, insects, and animals (Shahid et al., 2013). Although natural dyes are eco-friendly and biodegradable, they are unstable (Yamjala et al., 2016). On the other hand, synthetic dyes produced in controlled laboratory conditions show greater stability than natural dyes. Globally, the textile industry utilizes the highest proportion of dyes (Fang et al., 2004), which are often toxic to living beings and difficult to degrade (Fu and Viraraghavan, 2001). Upon coloring the fabrics, $10-15 \%$ of used dyes, fibers, and other components generally get discharged into the aquatic ecosystem (Chen et al., 2003). The dyes in the aquatic environment pose a major threat to the inhabitants (Sandhya et al., 2008). The presence of dyes inhibits photosynthetic activity and oxygen solubility at deeper layers of the water body by reducing the light penetration (Saratale et al., 2009). The dyes form a source of aromatic amines upon degradation, which, in turn, are considered as mutagenic, toxic, and carcinogenic, posing threats to living beings (Robinson et al., 2001; Ayed et al., 2011). Considering these detrimental effects of dye on the environment, safe disposal and successful decolorization of dyes becomes the utmost priority.

For dye decolorization and degradation, several methods such as coagulation/adsorption, electrolysis, ozonation, chemical oxidation, and ultrafiltration have generally been used (Zhang et al., 2004; Zhu et al., 2004). However, these methods have limited applicability due to their inefficiency, higher budget, and toxic intermediates (Verma et al., 2003; Zhang et al., 2004). The municipal sewage systems are not adequate to decolorize the water discharge efficiently due to the complex nature of pollutants and residuals from the by-products (Champagne and Ramsay, 2010). Hence, the biological degradation of dyes involving microbes is considered as one of the best methods (O'neill et al., 2000). This has been proven as a cost-effective and eco-friendly method that generates a significantly lesser amount of intermediate toxic compounds (Robinson et al., 2001; Chen et al., 2003). Biological methods include dye degradation by metabolic pathways, absorption, and accumulation by bacteria, fungi, yeast, and algae (Solís et al., 2012). Several studies have reported that bacterial strains possessing genes for azoreductase, laccase, and peroxidase, which act on the amine and aromatic structure of dye, make them suitable candidates for dye degradation (Chen et al., 2003; Babu et al., 2015). Several bacterial strains including Gram-negative and Gram-positive bacteria had been reported to show the dye decolorization ability, for example, Bacillus subtilus and Aeromonas hydrophila (Wuhrmann et al., 1980); Proteus mirabilis and Pseudomonas sp. (Saratale et al., 2011); Shewanella sp.; and other bacterial consortia (Moosvi et al., 2005).

Major challenges in bacterial dye degradation in the wastewaters include high salt concentration, various metals, and complex nature of wastes. Hence, most of the bacteria, though have shown a promise in the early experiments, fail to work efficiently at a larger scale (Mellado and Ventosa, 2003).
In recent years, halophilic bacterial strains have shown promise in dye decolorization (Amoozegar et al., 2011). With the potential to degrade dye, they can grow in a wide range of salinity, temperature, $\mathrm{pH}$, and elevated heavy metal concentrations (Margesin and Schinner, 2001; John et al., 2020).

In the present study, we have assessed the dye degradation potential of a halophilic bacterial strain Salinivibrio kushneri HTSP isolated from Marakkanam saltpan, Tamil Nadu, India. This saltpan is characterized by a large seasonal fluctuation of salinity, temperature, dissolved oxygen, and elevated levels of several heavy metals (John et al., 2019, 2020). Previous studies on this halophilic bacterium, S. kushneri HTSP (Proteobacteria, Gamma-proteobacteria, Vibrionales, and Vibrionaceae), revealed its ability to grow in a wide salinity range of $15-210$ ppt and $\mathrm{pH}$ range of 5-10, and it has tolerance to heavy metals including $\mathrm{Cu}, \mathrm{Zn}, \mathrm{Co}, \mathrm{Hg}, \mathrm{Cr}, \mathrm{Pb}$, and As (John et al., 2019). The analysis of whole-genome sequencing showed the presence of genes conferring resistance/tolerance to heavy metals and UV radiation, as well as those responsible for hydrocarbon degradation, by producing various enzymes, thus indicating the bioremediation potential of this bacterium in various industries and ecosystems (John et al., 2019). Though this species shows potential in dye decolorization, no studies have been attempted to prove this claim. Hence, to address this knowledge gap, we studied bio-decolorization of three dyes belonging to different classes using the S. kushneri HTSP strain: (i) Coomassie brilliant blue (CBB) G-250, a triphenylmethane dye commonly used in the textile industry and molecular biology laboratories (Rayaroth et al., 2015; Abbas et al., 2016); (ii) Safranin O, a quinone imine dye commonly used as a biological stain in the laboratories (Drabik et al., 2010; Sabnis, 2010); and (iii) Congo red, an azo dye, a known carcinogen, widely used in the paper, textile and other industries (Babu et al., 2013).

Industrialization is increasing at a faster pace and causing the rise of environmental pollution by producing millions of different chemicals including hydrocarbons, herbicides, pesticides toxic metals, and different dyes as either direct products or by-products (Amoozegar et al., 2011). Synthetic dyes and toxic structures of the dye-containing effluents pose a serious threat to aquatic life forms by causing toxicity to them (Georgiou et al., 2004; Supaka et al., 2004). Biological dye decolorization has been advocated as one of the most suitable methods to treat waste materials before discharge (Stolz, 2001). In this regard, we assessed the suitability of halophilic bacteria S. kushneri HTSP isolated from Marakkanam saltpan for decolorization of synthetic dyes. We analyzed the rate of bacterial decolorization of dyes using UV-Vis spectrophotometer and Fourier Transform Infrared (FTIR) spectrometer. We also performed in silico analysis to identify genes involved in dye decolorization in the previously reported S. kushneri HTSP genome.

\section{MATERIALS AND METHODS}

\section{Dyes and Chemicals}

Three dyes were used for dye decolorization experiments: Safranin, Congo red, and CBB G-250. All the dyes used in 
this study were purchased from Sigma-Aldrich (United States). Different concentrations were used for decolorization experiments and the desired concentrations were selected based on preliminary screening from 50 to $5,000 \mathrm{mg} / \mathrm{L}$. For conducting the experiments, 500-3,000 and 50-800 mg/L was selected for CBB G-250, Congo red, and Safranin, respectively. All the dye solutions were prepared in filter-sterilized $(0.2 \mu \mathrm{m})$ dye decolorization broth for avoiding nutrient loss. The working solutions were prepared using sterilized decolorization media for compensating the nutrient loss.

\section{Microorganisms and Inoculum Preparation}

Salinivibrio kushneri HTSP isolated from the Marakkanam salt pan $\left(12.13^{\circ} 02^{\circ} \mathrm{N} ; 79.58^{\circ} 12^{\circ} \mathrm{E}\right)$ was previously identified through a polyphasic taxonomic approach including morphological, biochemical, and molecular analysis (John et al., 2019). For the present study, the culture was revived from a stock kept in $80 \%$ glycerol at $-80^{\circ} \mathrm{C}$. These were transferred on to a fresh nutrient agar plate prepared in the source seawater $(120 \mathrm{ppt})$. The culture conditions including optimum salinity, temperature, $\mathrm{pH}$, and days of incubation were standardized. The bacterial strain was inoculated under aerobic conditions onto nutrient broth as well as agar with different ranges of salinity, from 15 to $60 \mathrm{ppt}$, and incubated at $27-37^{\circ} \mathrm{C}$ for $12 \mathrm{~h}$ to 2 days. The required salinity was obtained by mixing the source seawater $(200 \mathrm{ppt})$ with sterilized Milli Q water.

One loopful of overnight-grown culture was inoculated into the decolorization broth (5-g glucose, 2.5-g yeast extract, and $2.5 \mathrm{-g} \mathrm{NaCl}$ in a final volume of $500 \mathrm{ml}$ ) and incubated in a shaker incubator (aerobic) at $37^{\circ} \mathrm{C}$ for $6 \mathrm{~h}$. After $6 \mathrm{~h}$ (log phase of bacterial growth), the cells were harvested by a quick centrifuge at 3,000 rpm for $5 \mathrm{~min}$. The bacterial cells were resuspended in $0.8 \% \mathrm{NaCl}$, and the optical density at $600 \mathrm{~nm}$ was adjusted to $\sim 0.6-0.8\left(6 \times 10^{8} \mathrm{cell} / \mathrm{s} / \mathrm{ml}\right)$. The cell suspensions were used for further analysis.

\section{Decolorization Experiment}

Two hundred microliters of the bacterial cell suspension were inoculated onto different concentrations of different dyes (for $20 \mathrm{ml}$ ) and the tubes were incubated at $37^{\circ} \mathrm{C}$ for $48 \mathrm{~h}$ against a negative control, which contained only the dye in respective concentrations without the inoculum. The solution was withdrawn at an interval of $4 \mathrm{~h}$ for CBB G-250 and $6 \mathrm{~h}$ for Congo red and Safranin. The absorbance of the decolorized media solution (blank) was measured at $580 \mathrm{~nm}$ (CBB G-250), $490 \mathrm{~nm}$ (Congo red), and $530 \mathrm{~nm}$ (Safranin), respectively, using UV-Vis spectrophotometer against a blank of decolorization media without dye. The solution was centrifuged at $12,000 \mathrm{rpm}$ for $1 \mathrm{~min}$ before taking the absorbance for removing any suspended precipitates. All the experiments were performed in triplicates. The trial experiment was also conducted with a higher volume $(250 \mathrm{ml})$ and the same result was obtained. For the qualitative and quantitative analysis, the experiment was performed in $20 \mathrm{ml}$ volume.

Decolorization percentage was calculated using the formula:
Decolorization $(\%)=\left[\frac{\text { Initial absorbance }- \text { final absorbance }}{\text { Initial absorbance }}\right] * 100$

\section{Biodegradation Assay}

The dye degradation was further confirmed through spectral analysis of UV-Vis spectroscopy and FTIR spectroscopy.

\section{UV-Visible Spectroscopy}

For the UV-Vis spectral analysis of dye decolorization, the decolorized solution was scanned $(200-1,000 \mathrm{~nm})$ against a dye control and the peaks were cross-matched using a spectrophotometer (Shimadzu, UV-1800). The highest concentration of dye which was completely decolorized was chosen for this analysis against a dye control. The peaks obtained before and after decolorization were analyzed (Ali et al., 2009; Ayed et al., 2011).

\section{Fourier Transform Infrared Spectroscopy}

The functional groups of the degraded dyes were analyzed with FTIR spectroscopy. The biodegraded dye was collected after the experiment and the bacterial suspension was removed by centrifugation at $5,000 \mathrm{rpm}$ for $5 \mathrm{~min}$. The resulting supernatant solution was lyophilized and used for FTIR analysis. The highest concentration at which the dyes were completely decolorized was used as a test sample for FTIR analysis and the dyes in powder form were used as control. The mid-IR spectra of degraded dyes were obtained in the FTIR spectrophotometer by Shimadzu, IR Infinity 1 . The degraded dye sample was prepared by mixing 1 weight $\%$ of dye with 99 weight $\%$ of $\mathrm{KBr}$ and the mixture was ground well to make a paste of uniform consistency. The sample matrix was loaded in a $7-\mathrm{mm}$ Pellet Die of 7-mm Disc Holder Mount and pressed in $2 \mathrm{~T}$ Mini-Pellet Press (Specac Ltd.). The sample mixture was then analyzed using the instrument by mounting the sample on the sample holder using the ring holder and the transmittance scanned from the range of $4,000-400 \mathrm{~cm}^{-1}$ with a resolution of $1 \mathrm{~cm}^{-1}$ set for 20 scans per min (Babu et al., 2013). The obtained peaks were compared with the published reference dye peaks (Sigma-Aldrich, n.d.; Sun et al., 2013; Maity et al., 2015; Sahu and Patel, 2015; Asses et al., 2018).

\section{In silico Analysis of Salinivibrio kushneri HTSP Dye-Decolorizing}

The genome of S. kushneri HTSP was retrieved from the NCBI genome database (John et al., 2019, NCBI genome accession no. PXUD00000000) for analyzing dye-decolorizing genes. The genome was subjected to automatic annotation on the Rapid Annotations using Subsystems Technology webserver (Overbeek et al., 2014). The annotated genome was visually searched to identify the target genes, and a BLAST search was performed using the annotated genome against well-studied genes.

Azoreductase Clade III, a well-known decolorizing enzyme, was identified in the genome and compared with other bacterial species through phylogenetic analysis. The phylogenetic tree was constructed based on an amino acid sequence from the best BLASTp hits along with previously reported sequences 
(Kumaran et al., 2020). Pairwise and multiple sequence alignment was performed using the CLUSTAL W program and phylogeny was constructed using the Neighbor-Joining (NJ) method in MEGA (v 7.0, Kumar et al., 2016). Multispecies nitroreductase family protein of Bacilli (NCBI GenBank accession: WP_002358386) was used as an outgroup in the phylogenetic tree.

\section{Statistical Analysis}

All the data from dye decolorization assays were tested for statistical significance by comparing the mean of different test conditions using One-way ANOVA with the Tukey Scheffe alpha multiple comparison test. The data were checked for the normality by visual inspection and homogeneity of variance by Levene's test. The data were considered significant if $p<0.05$. The statistical analysis was performed using SPSS [V. 22, IBM SPSS Statistics for Windows, Armonk, NY (SPSS, 2013)].

\section{RESULTS AND DISCUSSION}

\section{In silico Analysis for Dye Decolorization Genes}

A total of 12 genes involved in the dye decolorization pathway were identified. These include genes encoding FMN-dependent NADH azoreductase Clade III, hydroxymuconate delta isomerase, maleylacetoacetate isomerase, cytidine deaminase, cytosine deaminase, ornithine cyclodeaminase, deoxycytidine triphosphate deaminase, tRNA-specific adenosine-34 deaminase, diamino hydroxyl phosphoribosyl amino pyrimidine deaminase, glucosamine-6-phosphate deaminase, adenosine deaminase, and porphobilinogen deaminase.
To ascertain the identity of the FMN-dependent NADPH azoreductase Clade III, the first enzyme in the decolorizing pathway (Dave et al., 2015), the amino acid sequence of the gene was compared with previously reported sequences through BLAST and NJ-based phylogeny. The phylogenetic reconstruction revealed that azoreductase of S. kushneri HTSP forms a separate clade supported by high bootstrap confidence (Figure 1).

The genomic assessment of this strain revealed the presence of genes involved in various mechanisms of dye decolorization, for example, the FMN-dependent $\mathrm{NADH}$ azoreductase is involved in cleaving the azo bonds of the dye and converting the dye into aromatic amines (Dave et al., 2015). The resultant aromatic amines and other functional groups would be further cleaved or reduced by genes involved in deamination and isomerization processes. Based on the genes found in the genome, we have predicted a dye decolorization pathway (Figure 2). However further analysis like NMR; GC/LC-MS is needed for the confirmation of formed intermediates. AZO reductase, a primary enzyme in the decolorization process, was compared with other known sequences from different bacterial strains. Though the sequences from the genus Salinivibrio including S. kushneri HTSP formed a separate clade in the phylogenetic tree, it was comparatively closer to clade III azoreductase than other classes (I, II, and IV) of azoreductases (Suzuki, 2019; Kumaran et al., 2020). Class III azoreductase is a flavin-dependent enzyme with a significant difference in substrate specificities (Bafana and Chakrabarti, 2008; Misal and Gawai, 2018). In general, azo, nitro compounds, and quinone are a better substrate for class III azoreductase (Liu et al., 2008; Suzuki, 2019) such as Congo red (Yang et al., 2011; Gao et al., 2015), dyes with methyl groups (Eslami et al., 2016).

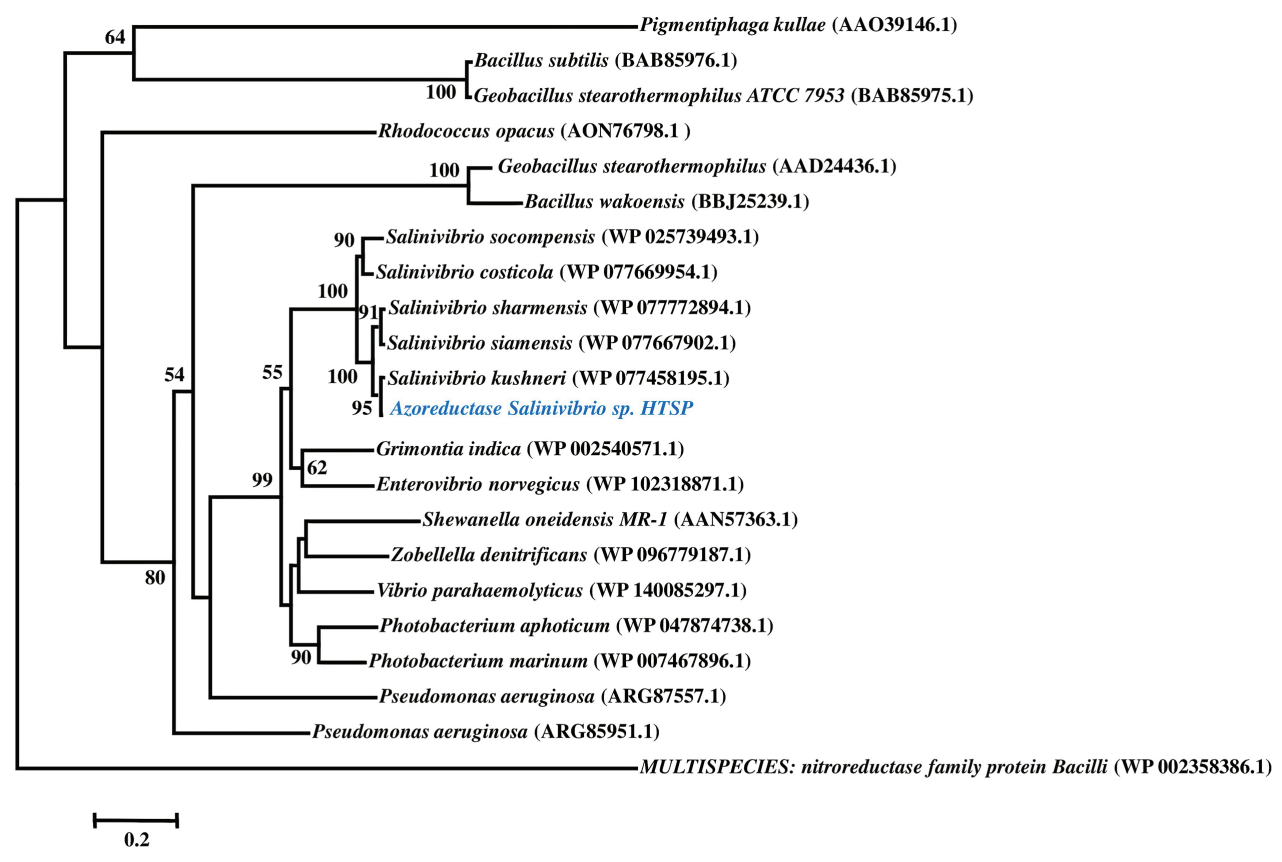

FIGURE 1 | Phylogenetic tree of azoreductase based on amino acid sequences. Amino acid sequences for nitroreductase is used as an outgroup. 

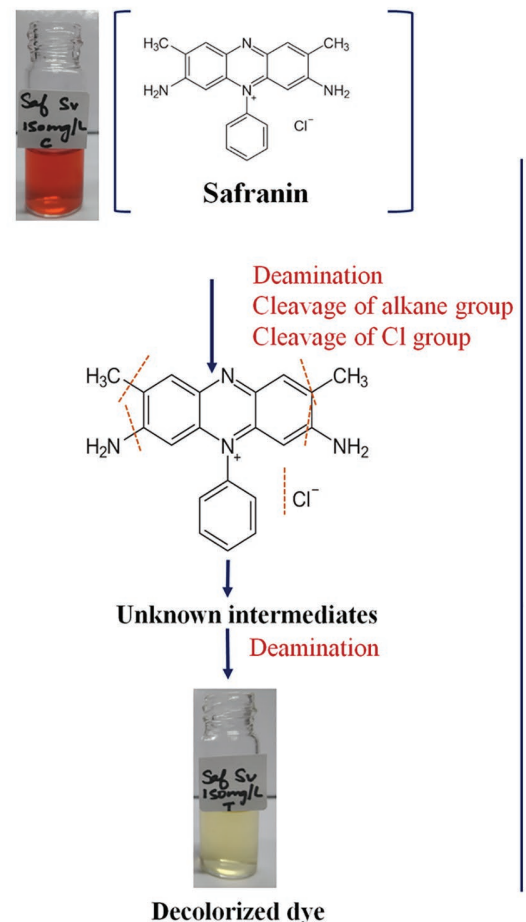

Decolorized dye
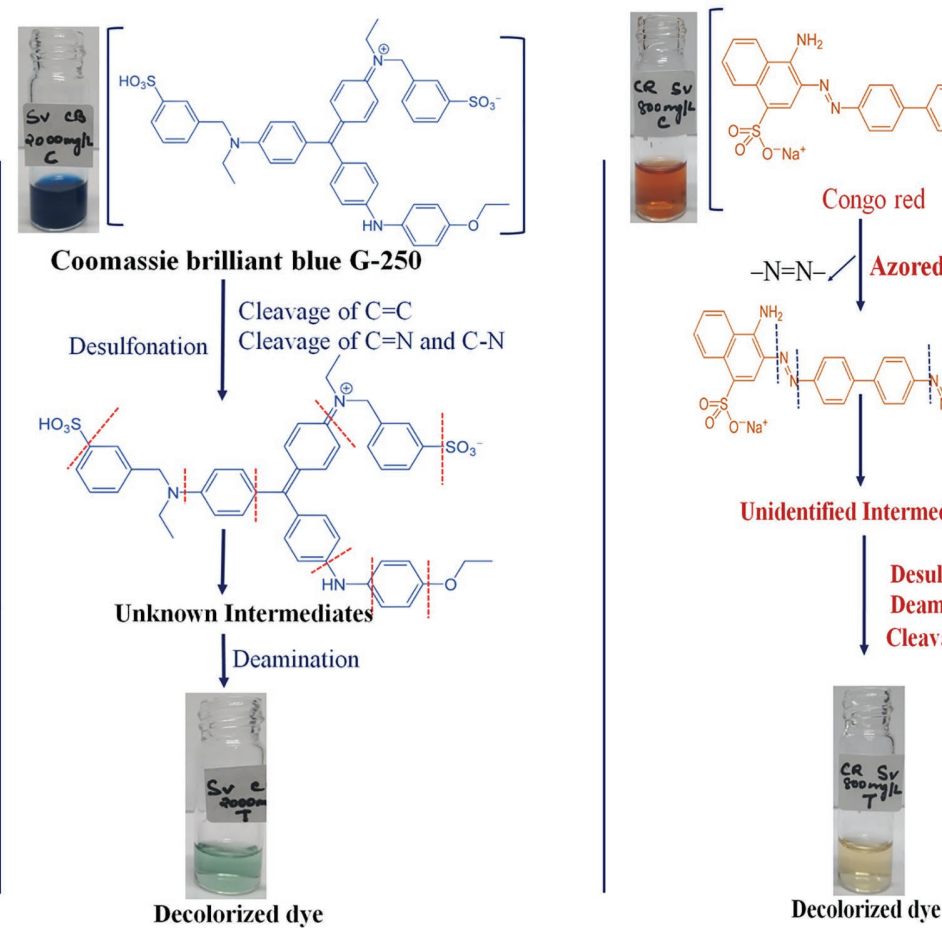

FIGURE 2 | Predicted mechanism of dye decolorization by Salinivibrio kushneri HTSP based on Fourier Transform Infrared (FTIR) peaks and functions of the genes identified. Functional group and bond cleavages are identified through the FTIR peaks.

Hence, it can be assumed that S. kushneri HTSP uses azoreductase to decolorize Congo red, Safranin (a dye with methyl group), and CBB G-250, indicating its potential for dye decolorization. The ability of different bacterial strains to decolorize different classes of dyes through the action of azoreductase has been reported earlier (Eichlerová et al., 2006; Amoozegar et al., 2011). For example, Halomonas elongate, a halophilic bacterium, is reported to decolorize mono and di azo dyes including methyl red, remazol black, and sulphonyl blue TLE (Eslami et al., 2016; Cao et al., 2017). Further, to ascertain our claim based on genomic analysis that the isolated strain can achieve dye decolorization, we performed decolorization assays on three dyes Congo red, Safranin, and CBB G-250 and analyzed using analytical methods of UV-Vis spectrophotometer and FTIR spectrometer, which is considered a gold standard for decolorization studies (Chen et al., 2008).

\section{Dye Decolorization by Salinivibrio kushneri HTSP}

The bacterial strain showed a luxuriant growth on a $60 \mathrm{ppt}$ solid plate after overnight incubation at room temperature $\left(\sim 29^{\circ} \mathrm{C}\right)$ with a pH of 7.4, and in the broth, it took $6 \mathrm{~h}$ to reach an optical density of $0.8-1$ at $600 \mathrm{~nm}$. Hence, decolorization assays were performed in $60 \mathrm{ppt}$ salinity conditions. Singlefactor analysis on ANOVA after complete decolorization of each dye at same time point showed the rate of decolorization between the different concentrations of dyes was statistically significant $(p<0.05)$. Salinivibrio kushneri HTSP significantly decolorized CBB G-250 dye for all concentrations within $48 \mathrm{~h}$ (Figure 3A). The percentage of decolorization was slow in the initial period of incubation and by $48 \mathrm{~h}$ almost $90 \%$ of the dye at all tested concentrations were completely decolorized. Within $48 \mathrm{~h}, 96 \pm 0.00,88 \pm 0.00,85 \pm 0.00,82 \pm 0.02$, and $73 \pm 0.00 \%$ dye was decolorized in $500,800,1,000,2,000$, and 3,000 $\mathrm{mg} / \mathrm{L}$ dye, respectively (Figure $\mathbf{3 A}$ ).

For Congo red dye decolorization, a significant color reduction was observed within $36 \mathrm{~h}$ of incubation. At $24 \mathrm{~h}, 92 \pm 0.00 \%$ dye was decolorized in $50 \mathrm{ppm}$ and for 150, 300, 600, and $800 \mathrm{ppm}$ the decolorization percentage was found to be $88 \pm 0.00,78 \pm 0.01,80 \pm 0.02$, and $69 \pm 0.00 \%$, respectively. After $36 \mathrm{~h}$, more than $90 \%$ of dye was decolorized in all concentrations (Figure 3B).

Salinivibrio kushneri HTSP decolorized Safranin completely in the lower concentration of 50 and $150 \mathrm{mg} / \mathrm{L}$ within $48 \mathrm{~h}$. However, with increasing dye concentration, the rate of decolorization decreased. A low level of decolorization, such as $79 \pm 0.02 \%$ for $300 \mathrm{mg} / \mathrm{L}, 25 \pm 0.00 \%$ for $600 \mathrm{mg} / \mathrm{L}$, and $22 \pm 0.00$ for $800 \mathrm{mg} / \mathrm{L}$ was obtained after $48 \mathrm{~h}$ (Figure 3C).

\section{Characterization of Samples After Degradation}

Shifts in the peaks were observed under UV-Vis spectroscopy between the test decolorized samples and the control. For CBB G-250, only one peak was observed in the control (at $585 \mathrm{~nm}$ ) and three peaks were observed in the test decolorized sample. For Congo red, three different peaks were observed in the 

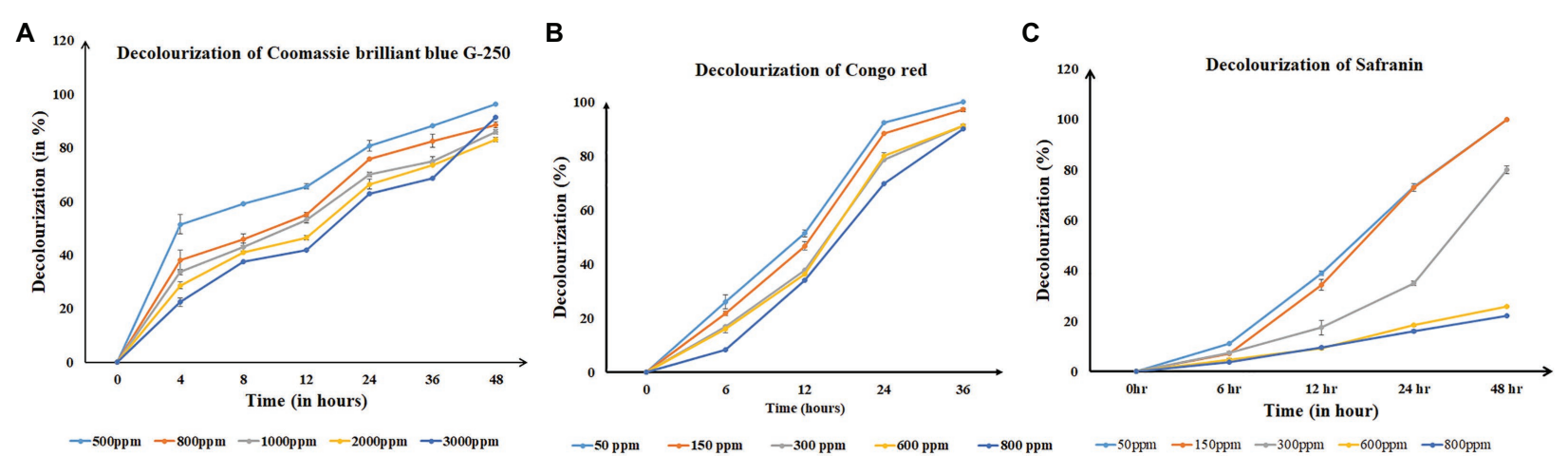

FIGURE 3 | Time-series graph denoting the decolorizing percentage of all three dyes at regular time intervals for S. kushneri HTSP, where, (A) is Coomassie brilliant blue $\mathrm{G}-250$ (CBB), (B) is Congo red, and (C) is Safranin.

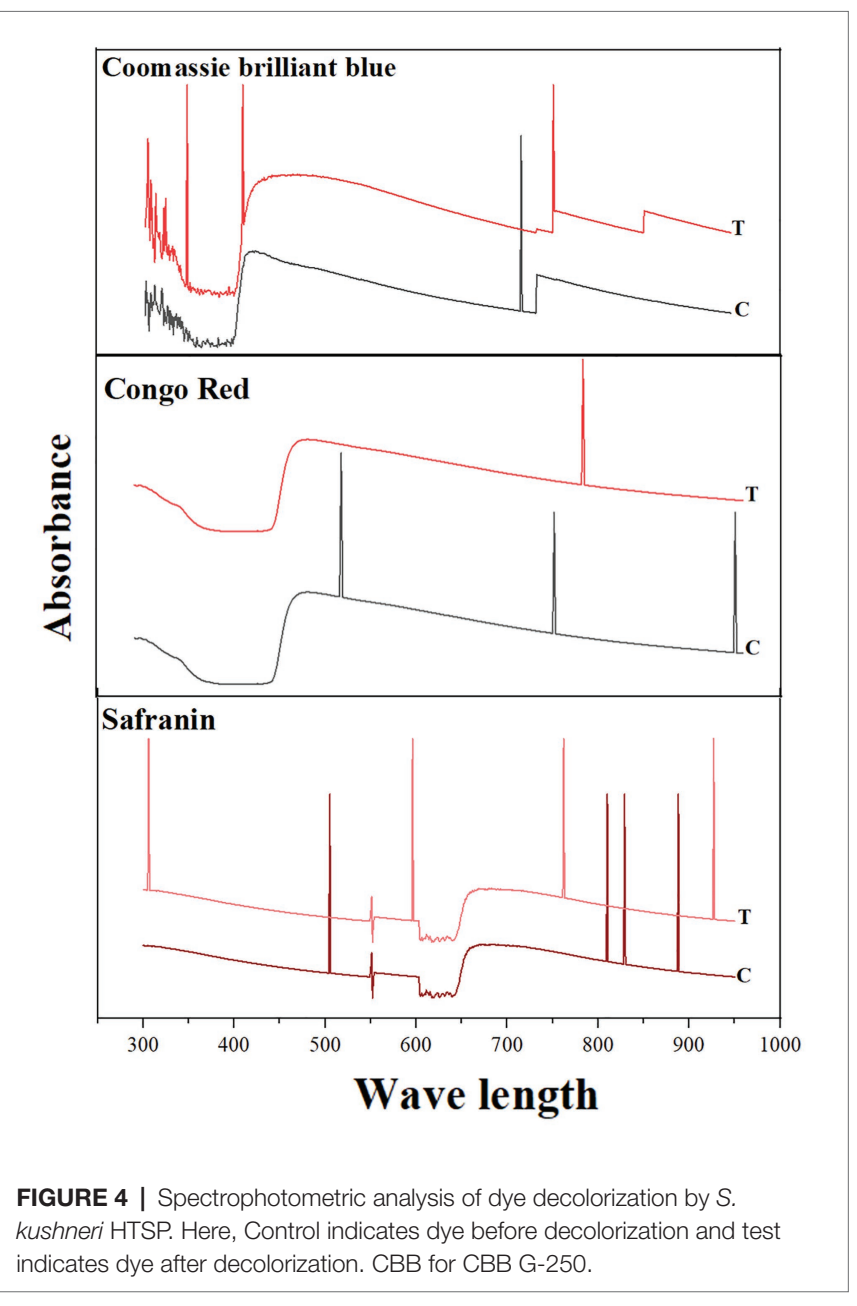

control, while only one peak after decolorization. For Safranin, four peaks were observed in both the control and the decolorized sample. However, the absorption wavelengths were different before and after decolorization: Peaks were observed at 888 , 829,810 , and $505 \mathrm{~nm}$ before decolorization and 927, 732, 596, and $306 \mathrm{~nm}$ after decolorization (Figure 4).
Further, various peaks were obtained in FTIR analysis of all three dyes corresponding to different vibrations of aromatic rings, aliphatic groups $\left(-\mathrm{CH}_{2},-\mathrm{CH}_{3}\right)$, and functional groups $\left(-\mathrm{NH},-\mathrm{SO}_{3} \mathrm{H}\right.$, and $\left.-\mathrm{SO}_{3}{ }^{-}\right)$. There were considerable variations observed in the functional groups before and after dye decolorization. For Congo red, 12 absorption peaks were observed before decolorization; however, no relevant peak was observed after decolorization (Figure 5A). For CBB G-250, 33 peaks were observed in the colored solution, while the number of peaks reduced to 30 after decolorization. The peaks spanned in the range of 422-3,200 $\mathrm{nm}$ wavelength with a majority between 1,000 and 2,000 $\mathrm{nm}$. However, peaks were not the same between colorized and decolorized solution, except for one at $454 \mathrm{~nm}$ (Figure 5B). For Safranin, 25 peaks in color solution and 24 peaks in decolorized solutions were observed. However, colored solution peaks were in the range of 3,400-4,000 $\mathrm{nm}$, and decolorized solution peaks in the range of 600-3,600 nm (Figure 5C). We used smoothened data for plotting the graph.

The functional group analysis using FTIR and peak analysis using UV-Vis spectroscopy before and after $36 \mathrm{~h}$ of decolorization of CBB G-250 (2,000 mg/L), Safranin (150 mg/L), and Congo red $(800 \mathrm{mg} / \mathrm{L})$ supported our predicted mechanism shown in Figure 2. In general, the peaks which are responsible for several different bonds and functional groups cleavage were identified and matched. The major peaks corresponded with cleavage of $\mathrm{N}=\mathrm{N}$ bonds, cleavage of aromatic rings, $\mathrm{OH}$ releasing, conversion of $\mathrm{SO}^{3-}$ to $-\mathrm{OH}$ groups, cleavage of $\mathrm{C}=\mathrm{C}$ and $\mathrm{C}=\mathrm{H}$ bonding, and cleavage of alkane group. On the contrary, after decolorization, the majority of the peaks were identified as hydroxy groups (-OH; Maity et al., 2015).

There were no significant peaks were observed after decolorization for Congo red. For Congo red dye (Figure 5A), observed peaks were identified as $\mathrm{N}-\mathrm{H}$ stretching $\left(3,468 \mathrm{~cm}^{-1}\right)$, C-O stretching $\left(1,226-1,179 \mathrm{~cm}^{-1}\right), \mathrm{S}=\mathrm{O}$ stretching $\left(1,059 \mathrm{~cm}^{-1}\right)$, and several unknown peaks found in the control sample were absent in the test conditions (Babu et al., 2013; Sun et al., 2013; Asses et al., 2018). For CBB G-250, the peaks in the range of 1,397-1,585 $\mathrm{nm}$ that corresponded with aromatic rings observed in the colored solution were mostly absent in the 

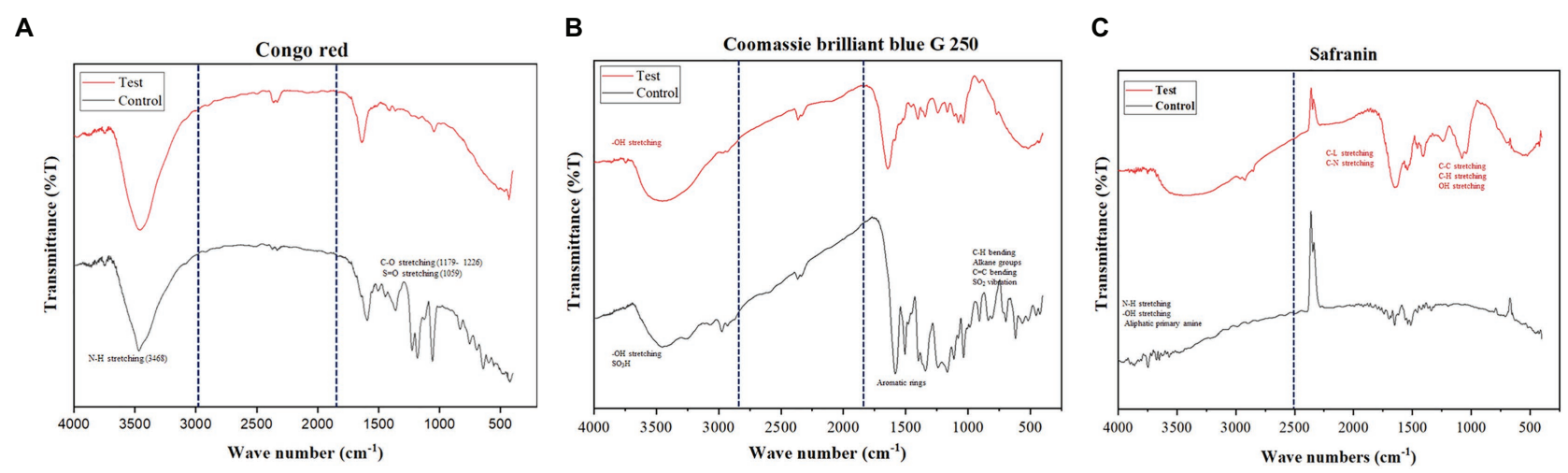

FIGURE 5 | Functional group analysis of all dyes before and after decolorization. Control indicates dye before decolorization and test indicates dye after decolorization. The important functional groups, aromatic rings, and aliphatic groups are highlighted in the control and in the test. Where, (A) is Congo red, (B) is CBB G 250, and (C) is Safranin.

decolorized solution. Sulfur dioxide vibration $\left(1,000-1,200 \mathrm{~cm}^{-1}\right)$, $\mathrm{C}=\mathrm{C}\left(985-618 \mathrm{~cm}^{-1}\right)$ bending, $\mathrm{CH}$ bending $\left(985-618 \mathrm{~cm}^{-1}\right)$, and alkane groups $\left(2,291-2,974 \mathrm{~cm}^{-1}\right)$ were observed in the colored solution but not in the decolorized solution, as shown in Figure 5B (Maity et al., 2015; Paz et al., 2017). For Safranin, the absorbance peaks observed were mainly aliphatic primary amine $\mathrm{N}-\mathrm{H}$ stretching $\left(3,000-3,560 \mathrm{~cm}^{-1}\right)$ and $-\mathrm{OH}$ stretching in the range of 3,589-4,000 $\mathrm{nm}$ in the control sample. However, in the decolorized test sample, the absorbance peaks varied: C-L stretching at $625 \mathrm{~nm}, \mathrm{C}-\mathrm{N}$ stretching 1,042-1,626 nm, C-C stretching 1,626 nm, C-H stretching 2,853-3,243 nm, and $-\mathrm{OH}$ stretching 3,283-3,564 nm (Babu et al., 2015; Sahu and Patel, 2015). The shift in the peaks suggests a breakdown of functional groups that may have changed the original structure of the dyes in the decolorized test samples (Chen et al., 2008; Ali et al., 2009).

Our results clearly indicate that $S$. kushneri HTSP could decolorize up to $3,000 \mathrm{mg} / \mathrm{L}$ CBB G-250; $300 \mathrm{mg} / \mathrm{L}$ for Safranin; and $800 \mathrm{mg} / \mathrm{L}$ for Congo red, which is significantly a higher concentration than previously reported. For example, Paz et al. (2017) showed that Bacillus aryabhattai could decolorize CBB G-250 up to $150 \mathrm{mg} / \mathrm{L}$; Babu et al. (2013) showed that Dietzia sp. decolorized Congo red up to $100 \mathrm{mg} / \mathrm{L}$. In addition, the time for decolorization was also found to be significantly less for S. kushneri HTSP than previously reported. Our results have shown that $S$. kushneri HTSP could decolorize a higher concentration of dyes at even a faster rate than previously reported halophilic bacteria such as Shewanella putrefacians and Halomonas sp. (Amoozegar et al., 2011; Gao et al., 2015). Previous studies on other bacteria also have reported a higher average time to decolorize the dyes used in this study even in comparatively lower concentrations (Babu et al., 2013; Paz et al., 2017).

\section{CONCLUSION}

Earlier studies have shown that S. kushneri HTSP has proven capacity to grow in a wide range of salinity, as well as the ability to tolerate/resist heavy metals and UV radiation (John et al., 2019), and now we report that this strain has capability to decolorize dyes in the higher concentration at a relatively faster rate. Thus, we argue that it can be potentially utilized for dye decolorization in wastewater treatment. However, further studies including cytotoxicity assays are to be conducted before using this strain at the industrial scales.

\section{DATA AVAILABILITY STATEMENT}

The data used in current study can be found in NCBI repository and all the accession numbers are provided in Materials and Methods section.

\section{AUTHOR CONTRIBUTIONS}

$\mathrm{JJ}$ and $\mathrm{RD}$ designed the research. JJ performed the decolourization experiments with KH. RD performed FTIR analysis with the help of $\mathrm{MD}$ and $\mathrm{DG}$. JJ, RD, and $\mathrm{AK}$ analyzed the data and drafted the final version of the manuscript to be published. All authors contributed to the article and approved the submitted version.

\section{ACKNOWLEDGMENTS}

We are grateful to the Director, CSIR-NIO, for providing the facilities necessary to carry out this study under OLP1707 and GAP2128. The computer-related studies were performed using the research computing facilities under GAP 0423: Biotechnology Information Systems project offered by the Department of Biotechnology, Govt. of India. JJ and AK would also like to thank Sathyabama Institute of Science and Technology for providing lab space and internal funding to carry out strain isolation and maintenance. The CSIR-NIO contribution number is 10295 . 


\section{REFERENCES}

Abbas, M., Cherfi, A., Kaddour, S., and Aksil, T. (2016). Adsorption in simple batch experiments of Coomassie blue G-250 by apricot stone activated carbon-kinetics and isotherms modelling. Desalin. Water Treat. 57, 15037-15048. doi: 10.1080/19443994.2015.1067871

Ali, H., Ahmad, W., and Haq, T. (2009). Decolorization and degradation of malachite green by Aspergillus flavus and Alternaria solani. Afr. J. Biotechnol. $8,1574-1576$

Amoozegar, M. A., Hajighasemi, M., Hamedi, J., Asad, S., and Ventosa, A. (2011). Azo dye decolorization by halophilic and halotolerant microorganisms. Ann. Microbiol. 61, 217-230. doi: 10.1007/s13213-010-0144-y

Asses, N., Ayed, L., Hkiri, N., and Hamdi, M. (2018). Congo red decolorization and detoxification by Aspergillus niger: removal mechanisms and dye degradation pathway. Biomed. Res. Int. 2018:3049686. doi: 10.1155/ 2018/3049686

Ayed, L., Mahdhi, A., Cheref, A., and Bakhrouf, A. (2011). Decolorization and degradation of azo dye Methyl Red by an isolated Sphingomonas paucimobilis: biotoxicity and metabolites characterization. Desalination 274, 272-277. doi: 10.1016/j.desal.2011.02.024

Babu, S. S., Mohandass, C., Raj, A. V., Rajasabapathy, R., and Dhale, M. A. (2013). Multiple approaches towards decolorization and reuse of a textile dye (VB-B) by a marine bacterium Shewanella decolorationis. Water Air Soil Pollut. 224:1500. doi: 10.1007/s11270-013-1500-x

Babu, S. S., Mohandass, C., Vijayaraj, A., and Dhale, M. A. (2015). Detoxification and color removal of Congo red by a novel Dietzia sp. (DTS26)-a microcosm approach. Ecotoxicol. Environ. Saf. 114, 52-60. doi: 10.1016/j.ecoenv.2015.01.002

Bafana, A., and Chakrabarti, T. (2008). Lateral gene transfer in phylogeny of azoreductase enzyme. Comput. Biol. Chem. 32, 191-197. doi: 10.1016/j. compbiolchem.2008.03.003

Cao, X., Di, M., and Wang, J. (2017). Expansion of the active site of the azoreductase from Shewanella oneidensis MR-1. J. Mol. Graph. and Model. 78, 213-220. doi: 10.1016/j.jmgm.2017.10.020

Champagne, P. -P., and Ramsay, J. (2010). Dye decolorization and detoxification by laccase immobilized on porous glass beads. Bioresour. Technol. 101, 2230-2235. doi: 10.1016/j.biortech.2009.11.066

Chen, B. -Y., Chen, W. -M., Wu, F. -L., Chen, P. -K., and Yen, C. -Y. (2008). Revealing azo-dye decolorization of indigenous Aeromonas hydrophila from fountain spring in Northeast Taiwan. J. Chin. Inst. Chem. Eng. 39, 495-501. doi: 10.1016/j.jcice.2008.05.004

Chen, K. -C., Wu, J. -Y., Huang, C. -C., Liang, Y. -M., and Hwang, S. -C. J. (2003). Decolorization of azo dye using PVA-immobilized microorganisms. J. Biotechnol. 101, 241-252. doi: 10.1016/s0168-1656(02)00362-0

Dave, S. R., Patel, T. L., and Tipre, D. R. (2015). "Bacterial degradation of azo dye containing wastes" in Microbial degradation of synthetic dyes in wastewaters. ed. S. Singh (Cham: Springer), 57-83.

Drabik, M., Touskova, J., Hanus, J., Kobayashi, H., and Biederman, H. (2010). Properties of composite films of titania nanofibers and Safranin O dye. Synth. Met. 160, 2564-2572. doi: 10.1016/j.synthmet.2010.10.006

Eichlerová, I., Homolka, L., Lisá, L., and Nerud, F. (2006). The influence of extracellular $\mathrm{H} 2 \mathrm{O} 2$ production on decolorization ability in fungi. J. Basic Microbiol. 46, 449-455. doi: 10.1002/jobm.200610064

Eslami, M., Amoozegar, M. A., and Asad, S. (2016). Isolation, cloning and characterization of an azoreductase from the halophilic bacterium Halomonas elongata. Int. J. Biol. Macromol. 85, 111-116. doi: 10.1016/j.ijbiomac.2015.12.065

Fang, H., Wenrong, H., and Yuezhong, L. (2004). Investigation of isolation and immobilization of a microbial consortium for decoloring of azo dye 4BS. Water Res. 38, 3596-3604. doi: 10.1016/j.watres.2004.05.014

$\mathrm{Fu}, \mathrm{Y}$., and Viraraghavan, T. (2001). Fungal decolorization of dye wastewaters: a review. Bioresour. Technol. 79, 251-262. doi: 10.1016/s0960-8524(01)00028-1

Gao, F., Ding, H., Shao, L., Xu, X., and Zhao, Y. (2015). Molecular characterization of a novel thermal stable reductase capable of decoloration of both azo and triphenylmethane dyes. Appl. Microbiol. Biotechnol. 99, 255-267. doi: 10.1007/s00253-014-5896-Z

Georgiou, D., Metallinou, C., Aivasidis, A., Voudrias, E., and Gimouhopoulos, K. (2004). Decolorization of azo-reactive dyes and cotton-textile wastewater using anaerobic digestion and acetate-consuming bacteria. Biochem. Eng. J. 19, 75-79. doi: 10.1016/j.bej.2003.11.003
John, J., Siva, V., Kumari, R., Arya, A., and Kumar, A. (2020). Unveiling cultivable and uncultivable halophilic bacteria inhabiting Marakkanam saltpan, India and their potential for biotechnological applications. Geomicrobiology 37, 691-701. doi: 10.1080/01490451.2020.1764676

John, J., Siva, V., Richa, K., Arya, A., and Kumar, A. (2019). Life in high salt concentrations with changing environmental conditions: insights from genomic and phenotypic analysis of Salinivibrio sp. Microorganisms 7:577. doi: 10.3390/ microorganisms7110577

Kumar, S., Stecher, G., and Tamura, K. (2016). MEGA7: molecular evolutionary genetics analysis version 7.0 for bigger datasets. Mol. Biol. Evol. 33, 1870-1874. doi: $10.1093 / \mathrm{molbev} / \mathrm{msw} 054$

Kumaran, S., Ngo, A. C. R., Schultes, F. P. J., and Tischler, D. (2020). Draft genome sequence of Kocuria indica DP-K7, a methyl red degrading actinobacterium. 3 Biotech 10:175. doi: 10.1007/s13205-020-2136-3

Liu, G., Zhou, J., Jin, R., Zhou, M., Wang, J., Lu, H., et al. (2008). Enhancing survival of Escherichia coli by expression of azoreductase AZR possessing quinone reductase activity. Appl. Microbiol. Biotechnol. 80, 409-416. doi: 10.1007/s00253-008-1555-6

Maity, M., Dolui, S., and Maiti, N. C. (2015). Hydrogen bonding plays a significant role in the binding of Coomassie brilliant blue- $\mathrm{R}$ to hemoglobin: FT-IR, fluorescence and molecular dynamics studies. Phys. Chem. Chem. Phys. 17, 31216-31227. doi: 10.1039/c5cp04661k

Margesin, R., and Schinner, F. (2001). Potential of halotolerant and halophilic microorganisms for biotechnology. Extremophiles 5, 73-83. doi: 10.1007/ s007920100184

Mellado, E., and Ventosa, A. (2003). "Biotechnological potential of moderately and extremely halophilic microorganisms" in Microorganisms for Health Care, Food and Enzyme Production. ed. J. L. Barredo (Kerala: Research Signpost), 233-256.

Misal, S. A., and Gawai, K. R. (2018). Azoreductase: a key player of xenobiotic metabolism. Bioresour. Bioprocess. 5:17. doi: 10.1186/s40643-018-0206-8

Moosvi, S., Keharia, H., and Madamwar, D. (2005). Decolourization of textile dye Reactive Violet 5 by a newly isolated bacterial consortium RVM 11.1. World J. Microb. Biot. 21, 667-672. doi: 10.1007/s11274-004-3612-3

O'neill, C., Lopez, A., Esteves, S., Hawkes, F., Hawkes, D., and Wilcox, S. (2000). Azo-dye degradation in an anaerobic-aerobic treatment system operating on simulated textile effluent. Appl. Microbiol. Biotechnol. 53, 249-254. doi: 10.1007/s002530050016

Overbeek, R., Olson, R., Pusch, G. D., Olsen, G. J., Davis, J. J., Disz, T., et al (2014). The SEED and the rapid annotation of microbial genomes using subsystems technology (RAST). Nucleic Acids Res. 42, D206-D214. doi: 10.1093/nar/gkt1226

Pandey, A., Singh, P., and Iyengar, L. (2007). Bacterial decolorization and degradation of azo dyes. Int. Biodeterior. Biodegradation 59, 73-84. doi: 10.1016/j.ibiod.2006.08.006

Paz, A., Carballo, J., Pérez, M. J., and Domínguez, J. M. (2017). Biological treatment of model dyes and textile wastewaters. Chemosphere 181, 168-177. doi: 10.1016/j.chemosphere.2017.04.046

Rayaroth, M. P., Aravind, U. K., and Aravindakumar, C. T. (2015). Sonochemical degradation of Coomassie brilliant blue: effect of frequency, power density, $\mathrm{pH}$ and various additives. Chemosphere 119, 848-855. doi: 10.1016/j. chemosphere.2014.08.037

Robinson, T., Mcmullan, G., Marchant, R., and Nigam, P. (2001). Remediation of dyes in textile effluent: a critical review on current treatment technologies with a proposed alternative. Bioresour. Technol. 77, 247-255. doi: 10.1016/ s0960-8524(00)00080-8

Sabnis, R. W. (2010). Handbook of biological dyes and stains: Synthesis and industrial applications. Hoboken: John Wiley \& Sons.

Sahu, M. K., and Patel, R. K. (2015). Removal of Safranin-O dye from aqueous solution using modified red mud: kinetics and equilibrium studies. RSC Adv. 5, 78491-78501. doi: 10.1039/C5RA15780C

Sandhya, S., Sarayu, K., Uma, B., and Swaminathan, K. (2008). Decolorizing kinetics of a recombinant Escherichia coli SS125 strain harboring azoreductase gene from Bacillus latrosporus RRK1. Bioresour. Technol. 99, 2187-2191. doi: 10.1016/j.biortech.2007.05.027

Saratale, R., Saratale, G., Chang, J. -S., and Govindwar, S. P. (2009). Decolorization and biodegradation of textile dye navy blue HER by Trichosporon beigelii NCIM-3326. J. Hazard. Mater. 166, 1421-1428. doi: 10.1016/j. jhazmat.2008.12.068 
Saratale, R. G., Saratale, G. D., Chang, J. -S., and Govindwar, S. P. (2011). Bacterial decolorization and degradation of azo dyes: a review. J. Taiwan. Inst. Chem. E. 42, 138-157. doi: 10.1016/j.jtice.2010.06.006

Shahid, A., Singh, J., Bisht, S., Teotia, P., and Kumar, V. (2013). Biodegradation of textile dyes by fungi isolated from North Indian Field soil. Environment Asia 6, 51-57. doi: 10.14456/ea.2013.18

Sigma-Aldrich, I. (n.d.). "Spectrum Table \& Chart".

Solís, M., Solís, A., Pérez, H. I., Manjarrez, N., and Flores, M. (2012). Microbial decolouration of azo dyes: a review. Process Biochem. 47, 1723-1748. doi: 10.1016/j.procbio.2012.08.014

SPSS (2013). IBM Corp. Released 2013. IBM SPSS Statistics for Windows, Version 22.0. Armonk, NY: IBM Corp.

Stolz, A. (2001). Basic and applied aspects in the microbial degradation of azo dyes. Appl. Microbiol. Biotechnol. 56, 69-80. doi: 10.1007/s002530100686

Sun, J., Li, Y., Hu, Y., Hou, B., Zhang, Y., and Li, S. (2013). Understanding the degradation of Congo red and bacterial diversity in an air-cathode microbial fuel cell being evaluated for simultaneous azo dye removal from wastewater and bioelectricity generation. Appl. Microbiol. Biotechnol. 97, 3711-3719. doi: 10.1007/s00253-012-4180-3

Supaka, N., Juntongjin, K., Damronglerd, S., Delia, M. -L., and Strehaiano, P. (2004). Microbial decolorization of reactive azo dyes in a sequential anaerobic-aerobic system. Chem. Eng. J. 99, 169-176. doi: 10.1016/j. cej.2003.09.010

Suzuki, H. (2019). Remarkable diversification of bacterial azoreductases: primary sequences, structures, substrates, physiological roles, and biotechnological applications. Appl. Microbiol. Biotechnol. 103, 3965-3978. doi: 10.1007/ s00253-019-09775-2

Vaghela, S. S., Jethva, A. D., Mehta, B. B., Dave, S. P., Adimurthy, S., and Ramachandraiah, G. (2005). Laboratory studies of electrochemical treatment of industrial azo dye effluent. Environ. Sci. Technol. 39, 2848-2855. doi: $10.1021 /$ es035370c

Verma, P., Baldrian, P., and Nerud, F. (2003). Decolorization of structurally different synthetic dyes using cobalt (II)/ascorbic acid/hydrogen peroxide system. Chemosphere 50, 975-979. doi: 10.1016/ s0045-6535(02)00705-1

Wuhrmann, K., Mechsner, K., and Kappeler, T. (1980). Investigation on rate-determining factors in the microbial reduction of azo dyes. Eur. J. Appl. Microbiol. Biotechnol. 9, 325-338.

Yamjala, K., Nainar, M. S., and Ramisetti, N. R. (2016). Methods for the analysis of azo dyes employed in food industry-a review. Food Chem. 192, 813-824. doi: 10.1016/j.foodchem.2015.07.085

Yang, X., Wang, J., Zhao, X., Wang, Q., and Xue, R. (2011). Increasing manganese peroxidase production and biodecolorization of triphenylmethane dyes by novel fungal consortium. Bioresour. Technol. 102, 10535-10541. doi: 10.1016/j. biortech.2011.06.034

Zhang, F., Yediler, A., Liang, X., and Kettrup, A. (2004). Effects of dye additives on the ozonation process and oxidation by-products: a comparative study using hydrolyzed C.I. Reactive Red 120. Dyes Pigments 60, 1-7. doi: 10.1016/ S0143-7208(03)00111-6

Zhu, J., Zheng, W., He, B., Zhang, J., and Anpo, M. (2004). Characterization of $\mathrm{Fe}-\mathrm{TiO}_{2}$ photocatalysts synthesized by hydrothermal method and their photocatalytic reactivity for photodegradation of XRG dye diluted in water. J. Mol. Catal. A Chem. 216, 35-43. doi: 10.1016/j. molcata.2004.01.008

Conflict of Interest: The authors declare that the research was conducted in the absence of any commercial or financial relationships that could be construed as a potential conflict of interest.

Copyright (c) 2020 John, Dineshram, Hemalatha, Dhassiah, Gopal and Kumar. This is an open-access article distributed under the terms of the Creative Commons Attribution License (CC BY). The use, distribution or reproduction in other forums is permitted, provided the original author(s) and the copyright owner(s) are credited and that the original publication in this journal is cited, in accordance with accepted academic practice. No use, distribution or reproduction is permitted which does not comply with these terms. 